\title{
INFLUENCE OF GASEOUS PLASMA TREATMENT ON FUNCTIONAL PROPERTIES OF COATED PAPERS
}

\author{
Matej Holc $^{1}$, Igor Karlovits ${ }^{2}$, David Ravnjak ${ }^{3}$ \\ Aleš Palatinus ${ }^{3}$, Ita Junkar ${ }^{1}$ \\ 1Jožef Stefan Institute \\ Slovenia \\ 2Pulp And Paper Institute \\ Slovenia \\ 3Vevče Paper Production Mill \\ Slovenia \\ (Received July 20I9)
}

\begin{abstract}
Three different types of paper with different coatings have been used in order to study the influence of gaseous plasma treatment on surface properties of paper. Radio frequency (RF) oxygen plasma was used for treatment of papers that contain different parts of organic and inorganic components in their coatings. Surface properties like surface morphology, roughness, surface energy, wettability, and chemistry were studied. The influence of plasma modification was also studied in terms of printability and paper gloss, which are one of the key parameters that dictate the use of such paper in desired applications. The results indicate that plasma modification of different types of coatings indeed influences paper printability as well as gloss function, which was shown to be highly connected with surface morphology, as micro- and nanopores were opened or formed due to selective plasma etching of organic part of the coating. Moreover, significant increase in surface energy was observed on all plasma treated papers, however this seemed not to influence much on the printing and gloss properties.
\end{abstract}

KEYWORDS: Gaseous plasma, paper, coating, surface energy, morphology, surface chemistry, gloss, printability.

\section{INTRODUCTION}

Paper is a versatile material, used in a wide variety of applications. Its major bulk component is cellulose, a polysaccharide. For use in specific applications, cellulose-based papers need to be modified to achieve desired qualities, such as weight, color, gloss, printability, or barrier 
properties. To this end, coatings may be applied. In the paper industry, there is a clear trend of applying synthetic or bio-based waterborne polymer coatings (Skácelová et al. 2016). These coatings may contain organic polymers, such as styrene-butadiene latex, polyester resins, starch, or various other binders or fillers. Additionally, it is possible to include particles of inorganic materials, such as the minerals kaolin and calcium carbonate $\left(\mathrm{CaCO}_{3}\right)$, as pigments or fillers, thus forming a polymer-particle matrix.

The inclusion of polymer coatings brings new challenges for printing and product processing, as it affects both surface morphology and chemistry. It improves the barrier properties of paper, but disrupts access to the internal void volumes. The porous structure of a particle-containing coating influences paper qualities such as ink setting and optical properties (Pykönen 2010). The cellulose, as well as any mineral and latex particles on the surface of coatings, are also typically covered by the polymers they are dispersed in, which affects the surface chemistry (Pykönen et al. 2009)

Plasma, as a surface modification method, is one of intriguing ways to alter the surface properties of paper. It is well known that exposure of materials to highly reactive plasma alters their surface properties without influencing the bulk attributes of the material (Vesel et al. 2018). In the case of organic materials, exposure to oxygen plasma will functionalize the materials (Vesel and Mozetič 2017) and increase their surface energy, making the material more hydrophilic, and thus more suitable for application of dyes, inks, etc. (Vesel and Mozetič 2018), (Camargo et al. 2017) or to make it antimicrobial (Vohrer et al. 2001). It can also enable protein immobilization (Zhao et al. 2016) This effect increases with a higher dose of reactive plasma species due to increased exposure time (Friedman 2008) or discharge power (Pawłat et al. 2016). Typically, the effect gradually decreases with time after treatment, which is known as ageing.

Morphology of materials can also be modified by plasma treatment through the process of etching, where matter is removed from the surface of the treated material. Surface morphology can be altered either due to physical sputtering or chemical etching (Vesel and Mozetič 2017) of the surface. Selective etching is also possible, wherein plasma etches away susceptible organic material, such as polymers, while resistant inorganic material remains intact (Cveblar et al. 2005).

So far, paper surfaces were plasma treated mostly to increase wettability through oxidation. Usually, uncoated paper was treated, both at low and atmospheric pressure. Vesel et al. (2007) used an inductively coupled, radio frequency $(\mathrm{RF})$ oxygen plasma at low pressure to treat ink-jet paper, which is cellulose-based and contains alkyl ketene dimer (AKD) and $\mathrm{CaCO}_{3}$. The wettability increased, and X-ray photoelectron spectroscopy (XPS) analysis showed oxidation and increased presence of calcium. Scanning electron microscopy (SEM) images at low magnification showed no visible change in surface morphology (Vesel et al. 2007). Pawłat et al. (2016) used an RF jet at atmospheric pressure to treat cellulose-based paper containing $\mathrm{CaCO}_{3}$ filler, and similarly noted increased wettability and oxidation, without drastic changes in surface morphology and Fouriertransform infrared (FTIR) spectra. Tian et al. (2012) used a commercially available plasma asher at low pressure to successfully increase the wettability of paper-based bioactive sensors, while Skácelová et al. (2016) used a diffuse coplanar surface barrier discharge (DCSBD) to increase wettability and oxidation of paper; ageing was also reported. Cornelius et al. (2017) treated paper handsheets with a dielectric barrier discharge (DBD) at atmospheric pressure. When using helium with a fraction of oxygen, they recorded oxidation, but observed no changes to surface roughness. Wettability increase, as measured by wicking, was observed only when helium with a fraction of $\mathrm{C} 3 \mathrm{~F} 6$ was used for generation of plasma. On the other hand, increase in surface roughness was reported following $\mathrm{DBD}$ treatment in a helium-oxygen mixture at atmospheric pressure. It was attributed to selective etching of organic material (cellulose fibers) over inorganic fillers $\left(\mathrm{CaCO}_{3}\right)$ (Dimitrakellis et al. 2017). 
Plasma treatment of pigment-coated paper was done by Pykönen et al. (2008), who have used different plasma treatments at atmospheric pressure: one corona treatment in air, one pilot scale experimental plasma in argon, and one laboratory scale plasma based on DBD in nitrogen. They found that all treatments increased surface energy, and thus wettability, through oxidation and increase in roughness, as determined by XPS and gloss measurement, respectively. An ageing effect was observed for the surface energy, but not for the oxidation level (Pykönen et al. 2009). Oxidation appeared to primarily affect the polymer dispersants. Further, plasma increased the surface atomic percentage of elements found in the coating pigments, indicating etching of the polymer matrix. The different pigment components of individual coatings also responded differently to the treatments (Pykönen et al. 2009). Tuominen et al. (2014), as well as Bollström et al. (2012) also treated pigment-coated paper with a corona treatment in air and with an atmospheric pressure plasma in argon; both increased wettability. The first study found surface oxidation, and a slight decrease in micro- or nanoscale surface roughness for different paper types; ageing was reported. The second study found increased surface energy with no changes in topography. In a paper by Vaswani, Koskinen and Hess (2005) plasma was used to achieve hydrophobic surfaces with the use of polymerized fluorocarbon films.

Pykönen et al. (2010) also studied offset printability after plasma treatment. While the corona and pilot scale treatments did not have a clear influence on print density, the laboratory scale treatment reduced it. The reason was a reduced surface strength due to micro-picking. Their work further indicates that plasma activation influences ink setting, in a manner which was correlated with the type of ink oil and its interactions with the plasma-treated surface. In the particular case of the pilot scale experimental plasma, the ink setting rate could be adjusted without influencing the final print quality. Karlovits and Lavrič (2018) printed with water based flexo inks on wax coated paper samples after plasma treatment, where the printability was improved. By fine-tuning the plasma treatment parameters, it should be possible to achieve the desired changes to the coating, which could improve its surface properties for specific application. Thus, the main motivation of our work was to systematically study the influence of oxygen plasma treatment of three different types of coatings in terms of altered surface properties, as well as printability and paper gloss.

\section{MATERIAL AND METHODS}

Pre-coated papers from different manufacturers and with different type of coatings were used for surface modification. For the purpose of this text, they were assigned the names paper 1, paper 2, and paper 3. Paper 1 is an offset paper made from recycled waste paper and bleached mechanical pulp. This paper consists of about $18 \%-24 \%$ of inorganic parts, and is coated with $0.5-1 \mathrm{~g} \cdot \mathrm{m}^{-2}$ of starch. Paper 2, the second offset paper, has deinked pulp, mechanical pulp, and consists of about $28 \%-32 \%$ of inorganic parts. It is coated by a combination of $\mathrm{CaCO}_{3}$ and pigment coating, and has the highest amount of inorganic components in the coating. Paper 3 is made from a combination of softwood (eucalyptus) and hardwood with production rests. This paper also has higher amount of surface coating (30\% of the paper weight), which contains $\mathrm{CaCO}_{3}$, kaolin fillers, as well as a latex binder. In order to study the influence of plasma treatment on these three types of paper, the papers were cut in pieces of $10 \times 10 \mathrm{~cm}^{2}$ and modified by plasma for $10 \mathrm{~s}$ or $60 \mathrm{~s}$.

Weakly ionized oxygen plasma was created in a discharge chamber by an inductively coupled $\mathrm{RF}$ discharge. The RF generator operates at a frequency of $27.12 \mathrm{MHz}$ and at about $500 \mathrm{~W}$. 
The generated plasma enables rather uniform treatment of the sample inside the reactor chamber. The pressure was set to $30 \mathrm{~Pa}$ and the treatment times were $10 \mathrm{~s}$ and $60 \mathrm{~s}$. The samples were treated on a glass table in the plasma reactor, as schematically presented in Fig. 1.

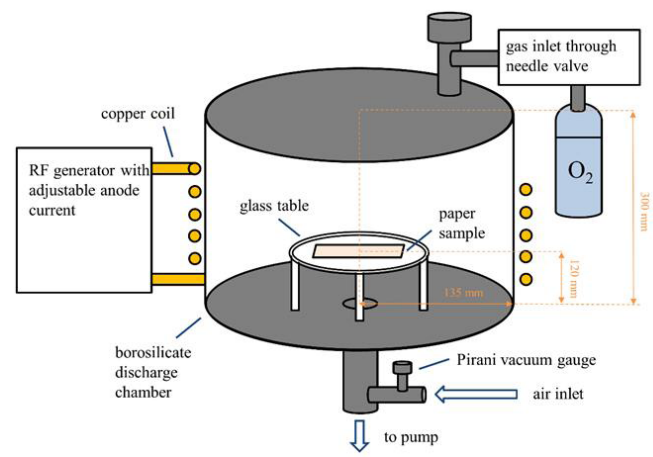

Fig. 1: Schematic representation of the plasma reactor used for treatment of paper.

Morphological properties of the samples were analyzed using SEM. Approximately $5 \times 5 \mathrm{~mm}$ pieces of treated and untreated paper were cut from the material. They were attached onto aluminum stubs using conductive carbon tape, their edges connected to the stub surface using carbon paste, and coated with a layer of gold approximately $10 \mathrm{~nm}$ thick using a Balzers SCD 050 sputter coater (Bal-Tec, Balzers, Liechtenstein). The SEM images were obtained using a Jeol JSM-7600F Schottky Field Emission SEM (Jeol Ltd., Tokyo, Japan).

Topographic changes of papers before and after plasma treatment were monitored with an atomic force microscope (AFM) (Solver PRO, NT-MDT, Moscow, Russia) in the tapping mode in air. The samples were scanned with a standard Si cantilever with a force constant of $22 \mathrm{~N} . \mathrm{m}-1$ and at a resonance frequency of $325 \mathrm{kHz}$.

The surface roughness was measured with a TR200 stylus profilometer using a diamond tip with $2 \mu \mathrm{m}$ radius. The following measurement parameters were used: sampling length $0.80 \mathrm{~mm}$ and traversal speed $0.135 \mathrm{~mm} \cdot \mathrm{s}^{-1}$. The measured average surface roughness parameter, $\mathrm{Ra}$, is compliant to the geometric product specification standards (ISO 4287: 1997 and ISO 12218: 1997, 2004). The samples were measured in 3 different areas by measuring the vertical and horizontal scanning lines.

The surface energy was measured with an automated contact angle tester according to the Tappi T $5580 \mathrm{~m} 97$ standards and by using two test liquids. The surface energy was calculated by the harmonic mean method. The influence of ageing was studied on paper 3 in order to observe stability of surface modification. Wettability and surface energy was measured after storage of paper 3 at the room temperature and at constant humidity for one and three weeks.

The surface of the sample was analyzed with the XPS instrument PHI TFA XPS (Physical Electronics, Ismaning, Germany). The base pressure in the XPS analysis chamber was about $6 \times 10-8 \mathrm{~Pa}$. The samples were excited with $\mathrm{X}$-rays over a $400-\mu \mathrm{m}$ spot area with monochromatic $\mathrm{Al}$ source at radiation energy of $1486.6 \mathrm{eV}$. The photoelectrons were detected with a hemispherical analyzer positioned at an angle of $45^{\circ}$ with respect to the normal of the sample surface. The energy resolution was about $0.5 \mathrm{eV}$. Survey-scan spectra were obtained at pass energy of $187.85 \mathrm{eV}$. Since the samples are insulators, we used an additional electron gun to allow for surface neutralization during the measurements. All spectra were referenced to the main $\mathrm{C} 1 \mathrm{~s}$ peak of the carbon atoms, 
which was assigned a value of $284.8 \mathrm{eV}$. The XPS spectra were measured for an untreated sample and samples treated by oxygen plasma after 10 and $60 \mathrm{~s}$ of treatment.

The paper gloss levels were measured using a Lehmann gloss meter, which uses the Tappi, ANSI T 480 om- 15 standard, where the specular gloss of paper is measured at $75^{\circ}$ ( $15^{\circ}$ from the plane of paper) with converging beam geometry.

To test the printability, we have determined the ink levelling and ink absorbency of the untreated and plasma treated samples. The test uses the special porosimetric $\mathrm{K} \& \mathrm{~N}$ testing ink, which contains parts of pigments and parts of dyes, therefore the ink is absorbed to different depths in the paper structure. The ink levelling, which is influenced by the surface roughness and porosity, was measured through the print gloss measurement. The method is the same as for paper gloss, except that the samples were printed with suitable inks. The printing was done on a Pruefbau printability tester using the standard inking and printing speed of $1 \mathrm{~m} . \mathrm{s}-1$ and a printing pressure of $120 \mathrm{kPa}$.

To obtain even inking, we have applied the ink using a L\&W GFL ink automated wipe off tester and evaluated the luminance factors using an X-Rite directional geometry spectrophotometer. To measure changes in ink absorbency, which influences optical parameters such as ink density, lightness and brightness values as well gloss values, the $\mathrm{K} \& \mathrm{~N}$ ink absorption test was carried out according to SCAN-P 70:09. The test samples were printed with a suitable ink and were allowed to absorb the ink for $120 \mathrm{~s}$. The wiped off samples were measured with an i1Pro 2 spectrophotometer with measuring mode M1 (D50 standard illuminant, $2^{0}$ standard observer and $0: 45 \mathrm{c}$ directional geometry). The appropriate absorbency values were calculated according to Eq. 1 and are reported as a percentage:

$$
A=\frac{100 \cdot\left(R_{\infty}-R_{y}\right)}{R_{\infty}}
$$

where: $\mathrm{R}_{\mathrm{y}}$ - luminance factor of stained area (\%) and $\mathrm{R}_{\infty}(\%)$ is the intrinsic luminance factor of paper.

\section{RESULTS AND DISCUSSION}

Changes in the surface morphology of the three different paper types were assessed from SEM and AFM images. In Fig. 2, it can be clearly seen that plasma treatment influences the surface morphology of paper, especially after the longer treatment time (60 s). Nice examples of kaolin structures were revealed after plasma treatment, and can be observed on paper 2 and paper 3, especially after $60 \mathrm{~s}$ of treatment. In the case of paper 3, plasma obviously opens the micropore structure. Similar open structures were also observed in the case of paper 1, which appears to show a completely different morphology in comparison to paper 2 and paper 3 , but nonetheless, pores with a diameter of about $1 \mu \mathrm{m}$ can be seen on the surface. Additionally, nanostructures appear on the surface of paper 1 and also paper 2. Therefore, paper 1 exhibits a unique combination of nanotopography and micropore structure. In the case of paper 2, no significant changes in surface morphology on the micro scale were observed by SEM analysis, but nanotopography is present, while in the case of paper 3, no nanostructuring of the surface is observed, only opened micro porous structures. 


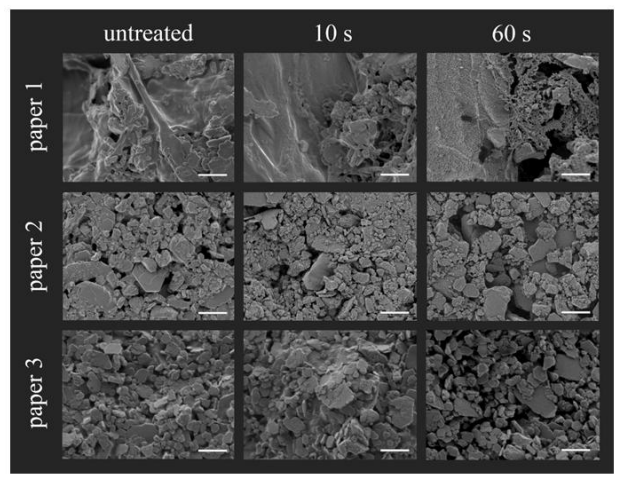

Fig. 2: SEM images of untreated and plasma treated paper surfaces. Taken at 20,000 $\times$ magnification. Size of the scale bar is $1 \mu \mathrm{m}$.

The morphology of paper 2 was further studied by AFM analysis, as seen in Fig. 3. In this case, surface nanostructuring can be observed already after $10 \mathrm{~s}$ of plasma treatment. It is hard to provide reliable information about the surface roughness of untreated and plasma treated samples from AFM measurements, as the surface is not homogeneous, and thus, the measured surface roughness is highly influenced by the area of analysis. For example, if the area of analysis is done on surfaces with more kaolin particles, the change in surface roughness is not as obvious, as kaolin crystals are not etched by plasma. On the other hand, in case of organic parts of the coating, the increase in roughness can be detected, as the surface becomes more nanostructured compared to the untreated surface.

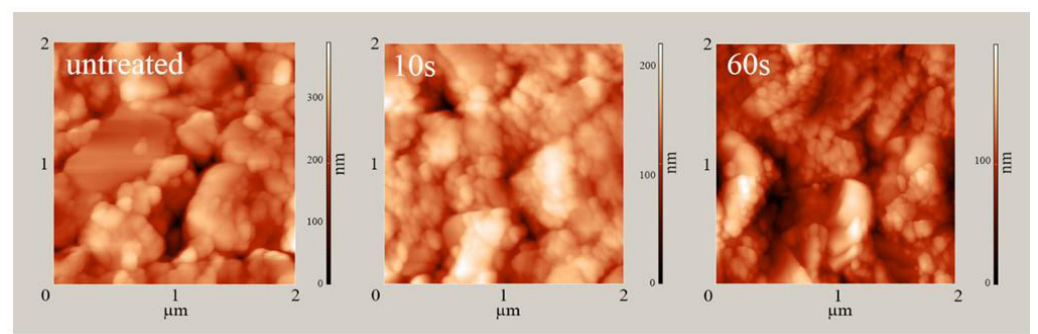

Fig. 3: AFM images of the untreated, 10 s and 60 s plasma treated surfaces of paper 2.

Results of the average surface roughness measurements of unprinted papers before and after plasma treatment are presented in Fig. 4 (a), while the results for the printed papers before and after plasma treatment are presented in Fig. 4 (b). 


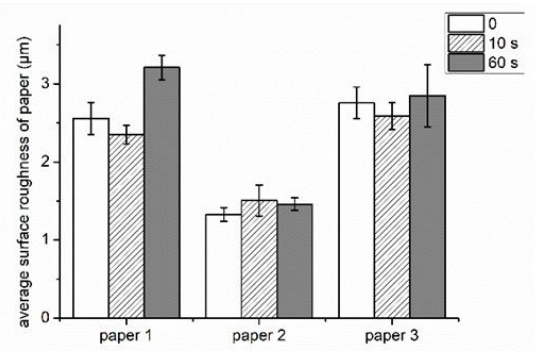

(a)

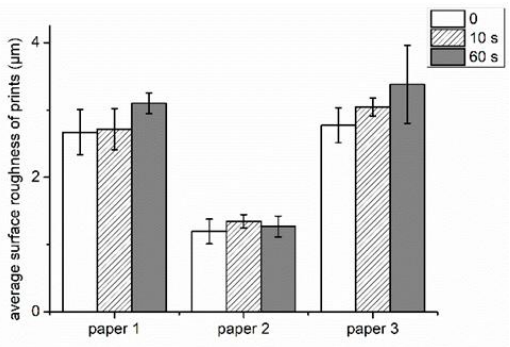

(b)

Fig. 4: Average surface roughness ( $R$ a) determined by profilometer analysis. (a) Ra of untreated and plasma treated paper surfaces; (b) Ra of untreated and plasma treated, subsequently printed paper surfaces.

A small decrease in surface roughness of paper 1 was observed after $10 \mathrm{~s}$ of plasma treatment, while after $60 \mathrm{~s}$ of treatment, a small increase in Ra was observed, as seen in Fig. 4a. A similar trend was observed in the case of paper 3, as seen in Fig. 4a. Paper 2 had the lowest roughness value among all papers, and a different interaction of plasma with this paper was observed. After $10 \mathrm{~s}$ of treatment, there was a slight increase in $\mathrm{Ra}$, and no significant changes were observed after $60 \mathrm{~s}$ of treatment. When evaluating surface roughness of the printed papers, as seen in Fig. 4b, it can be seen that roughness of paper 2 again is the least influenced by plasma treatment. For the case of paper 1 and 3, an increase in surface roughness from the initial value can be observed after the longer treatment time. The printed paper 1 exhibits an increase in Ra value from $2.67 \mu \mathrm{m}$ (initial printed sample without plasma treatment) to about $2.72 \mu \mathrm{m}$ and $3.10 \mu \mathrm{m}$ for 10 and $60 \mathrm{~s}$ treatment, resp. A similar trend was observed in case of paper 3 .

Surface wettability and surface energy results are collected in Tab. 1. Differences already exist in the initial wettability of papers. The highest water contact angle (WCA) was measured on paper 1 , with a WCA of about $113^{\circ}$, followed by paper 3 with WCA of about $105^{\circ}$, while paper 2 had the lowest WCA of about $63^{\circ}$. Changes in wettability show that all plasma treated surfaces become hydrophilic already after $10 \mathrm{~s}$ of treatment. The longer treatment time slightly improves wettability in case of paper 1 and 3, while in case of paper 2, conversely, a slight increase in wettability was observed. The increase in surface energy was also observed on all plasma treated papers. The initial surface energies of paper 1 and 2 were comparable, about $45.7 \mathrm{mN} \cdot \mathrm{m}^{-1}$ and $45.3 \mathrm{mN} \cdot \mathrm{m}^{-1}$, respectively, while the surface energy of paper 3 was lower, at $24.9 \mathrm{mN} \cdot \mathrm{m}^{-1}$. A comparable surface energy after $60 \mathrm{~s}$ of plasma treatment was measured on the paper 1 and 3 , followed by a slightly lower value for paper 2 . Interestingly, as paper 3 exhibited the lowest initial surface energy, in this case, the highest increase in surface energy was obtained. It seems that paper 3 was the most influenced by plasma treatment in terms of both surface wettability and energy, as in this case, the highest increases were observed. The offset paper 2 seems to be the least influenced by plasma treatment in terms of surface wettability and energy. The influence of so-called ageing of plasma treated surfaces was also studied on paper 3. It was observed that wettability has slightly decreased with time, as the WCA increased from about $18^{\circ}$ for freshly treated paper to about $31^{\circ}$ after one week of storage, and after three weeks reached a constant value of about $36^{\circ}$. A similar effect was observed in the case of surface energy, which increased from the initial $69.6 \mathrm{mN} \cdot \mathrm{m}^{-1}$ to $64.3 \mathrm{mN} \cdot \mathrm{m}^{-1}$ after one week of storage, and finally reached a constant value at about $62.1 \mathrm{mN} \cdot \mathrm{m}^{-1}$. It should also be noted that all plasma treated surfaces were highly 
hydrophilic and that both wettability and surface energy were close to the detection limit of our measuring method.

Tab. 1. Recorded WCA values and surface energy for the untreated and plasma treated paper samples.

\begin{tabular}{|l|c|c|c|c|c|c|c|c|c|}
\cline { 2 - 10 } \multicolumn{1}{c|}{} & \multicolumn{3}{c|}{ paper 1 } & \multicolumn{3}{c|}{ paper 2 } & \multicolumn{3}{c|}{ paper 3 } \\
\hline Treatment $(\mathrm{s})$ & 0 & 10 & 60 & 0 & 10 & 60 & 0 & 10 & 60 \\
\hline WCA $\left(^{\circ}\right)$ & 113.0 & 20.1 & 14.4 & 63.3 & 26.6 & 32.0 & 104.9 & 26.1 & 18.5 \\
\hline surface energy $\left(\mathrm{mN} \cdot \mathrm{m}^{-1}\right)$ & 45.7 & 68.9 & 70.9 & 45.3 & 66.5 & 63.7 & 24.9 & 66.6 & 69.6 \\
\hline
\end{tabular}

Chemical analysis of the surface was also studied in order to provide more insights into the surface modification of coated papers by plasma. In all cases, an increase in oxygen content and a decrease in carbon content were observed, as seen in Fig. 5. No significant changes were apparent between the $10 \mathrm{~s}$ and $60 \mathrm{~s}$ treatment times, thus only results for untreated and $60 \mathrm{~s}$ treated surfaces are presented in Fig. 5. The initial O/C ratio is the highest for paper 2, about 0.75, while more comparable, lower $\mathrm{O} / \mathrm{C}$ ratios are observed in case of paper 1 and 3 , about 0.47 and 0.46 , resp. After plasma treatment, the highest increase in the $\mathrm{O} / \mathrm{C}$ ratio was observed in the case of paper 3 , from 0.46 to about 1.68 , followed by paper 2 , where the initial $\mathrm{O} / \mathrm{C}$ ratio was about 0.75 and increased to 1.89 . The smallest increase in the $\mathrm{O} / \mathrm{C}$ ratio was observed in case of paper 1 , from about 0.47 to about 0.83 . Moreover, an increase in elements from the inorganic parts of the coating can be observed for all plasma treated samples, as increase in the presence of $\mathrm{Ca}, \mathrm{Al}$ or $\mathrm{Si}$ atoms is apparent.

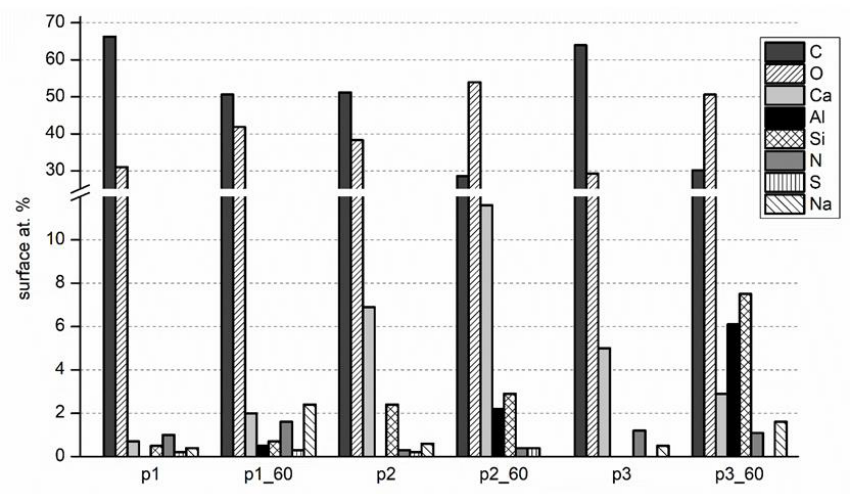

Fig. 5: Concentration of elements (in atomic \%) on untreated and plasma treated paper surfaces as determined by XPS. p1: paper 1, untreated; p1_60: paper 1, treated for 60 s; p2: paper 2, untreated; 22_60: paper 2, treated for $60 \mathrm{~s}$; 3 3: paper 3, untreated; 3 3_60: paper 3, treated for $60 \mathrm{~s}$.

The results of the unprinted papers before and after plasma treatment are presented in Fig. 6a. It seen that the highest initial gloss is measured for paper 2, but in this case, plasma treatment also seems to reduce the gloss, especially after $10 \mathrm{~s}$ of treatment. For paper 1, a slight reduction in paper gloss is also observed after plasma treatment, while in the case of paper 3 , an increase in gloss is observed after $10 \mathrm{~s}$ of treatment. 


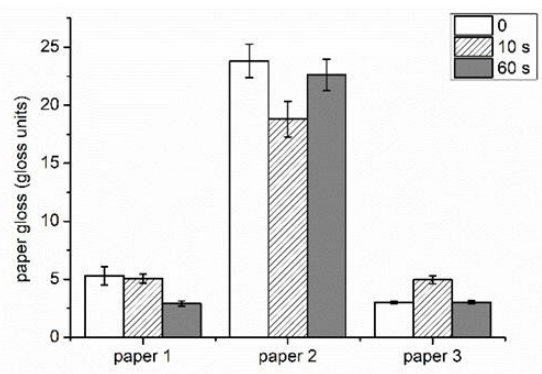

(a)

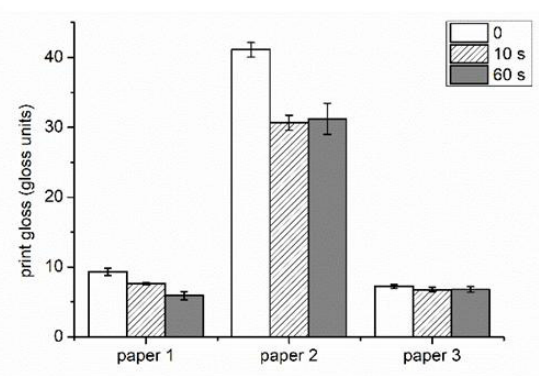

(b)

Fig. 6: Gloss values recorded for untreated and plasma treated paper samples. (a) paper gloss values; (b) print gloss values.

For the case of print gloss, as seen in Fig. 6b, paper 2 again has the highest gloss units, which are reduced after 10 and $60 \mathrm{~s}$ of plasma treatment. For paper 1 and 3, no significant changes in gloss of printed papers were detected.

The ink absorbency calculated values are presented in Fig. 7. It can be observed that paper 1 has the highest initial ink absorbency value, about 7\%, followed by paper 3 with about $6 \%$ and paper 2 with about 4\%. After $10 \mathrm{~s}$ of plasma treatment, increases in absorbency for paper 1 and 3 was observed, while in case of paper 2, the absorbency remains unchanged. Longer plasma treatment $(60 \mathrm{~s})$ results in decreases in ink absorbency for papers 1 and 3, practically to the level of the initial absorbency value in case of paper 1 . Again, practically no changes in absorbency were detected in the case of paper 2 .

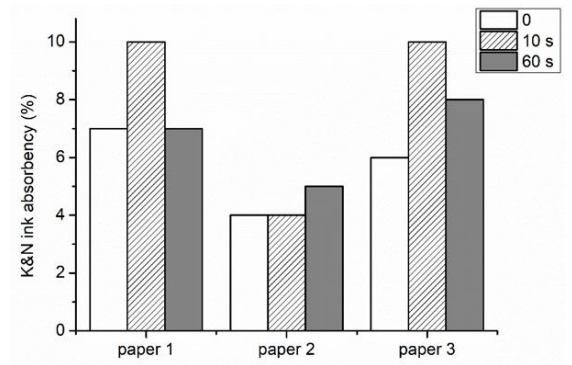

Fig. 7: KE'N ink absorbency values calculated for the untreated and plasma treated paper samples.

Plasma treatment significantly influences on surface morphology, especially after longer treatment times. According to SEM analysis, the $60 \mathrm{~s}$ treatment time of paper 1 and 3 opens their microporous structure. This occurs due to preferential plasma etching of the organic part of the coating, which masks the inorganic particles of the coating. Paper 1 contains the highest percentage of organic components in its coating, as the coating is mainly composed of starch. Thus, in this case, after the longer plasma treatment time $(60 \mathrm{~s})$, etching of the organic part of the coating is the most apparent. Paper 3 also contains a significant amount of organic materials in the coating, therefore similar micropores open, but the $\mathrm{CaCO}_{3}$ and kaolin particles remain intact. Similar effects were found for plasma treatment of uncoated paper, where Dimitrakellis et al. (2017) noted preferential etching of cellulose over $\mathrm{CaCO}_{3}$ particles, as well as coated paper, where plasma oxidation and etching primarily affected the polymer matrix of the coating (Pykönen 
et al. 2009). In the case of paper 1 and 2, nanostructuring of the surface was also observed. The morphology of paper 2 is the least influenced by plasma, as even after longer treatment time, no significant changes in microporous structures were observed. However, as revealed by AFM and higher magnification SEM images, slight nanostructuring of the surface does appear. The nanostructuring of the surface is well known in the case of plasma treatment of polymers (Junkar 2013), where selective etching of the polymer matrix can be observed.

The SEM morphology results can be well correlated with roughness measurements, as the opening of micropores by plasma can be correlated with the increase in the Ra values for papers 1 and 3. On the other hand, almost negligible changes in Ra values were observed in case of paper 2 , which correlates with the fact that on this paper, no changes in microporous structures were detected. Similar results were observed on printed papers, as the roughness increased for paper 1 and 3 . The increased roughness could be to some extent correlated with the building up of ink due to a rougher surface.

Regarding surface wettability and surface energy, paper 2 again stands out, as it has the lowest increase in wettability as well as in surface energy. However, it should be noted that this paper initially has the most hydrophilic character, as WCA is about $63^{\circ}$, while in case of paper 1 and 3 , the WCA is about $113^{\circ}$ and $105^{\circ}$, respectively. The highly improved wettability of paper 1 and 3 could be attributed to the opening of micropores on the surface, which allows penetration of water into the porous paper structures. In all cases, the increase in wettability can also be attributed to preferential etching and removal of the organic hydrophobic parts of the coating, as well as to newly formed oxygen functional groups on the surface of coating. This was confirmed by XPS analysis, as in all cases, an increase in oxygen atoms and decrease in carbon content was observed. The SEM and XPS results show that paper 1 has the most organic parts in the coating, which can easily be functionalized and nanostructured by plasma. According to the manufacturers, the coating is mainly made from starch. Thus in case of paper 1 , primarily the competition between etching and functionalization of organic parts of the coatings takes place during plasma treatment. However, in case of papers 2 and 3, the high increase in oxygen is not only due to functionalization, but can mainly be assigned to removal of organic parts of the coating (etching) and revealing the inorganic parts of the coatings rich with oxygen, such as calcium carbonate $\left(\mathrm{CaCO}_{3}\right)$, and kaolin $\left(\mathrm{Al}_{2} \mathrm{Si}_{2} \mathrm{O}_{5}(\mathrm{OH})_{4}\right)$ (Jikan et al. 2017).

Moreover, in XPS analysis, presence and increases in atomic concentrations of inorganic components like $\mathrm{Ca}, \mathrm{Al}$ or $\mathrm{Si}$ were observed on the surface after plasma treatment. Differences in chemical composition correspond well with the type of coating. For example, the initial atomic concentration of $\mathrm{Ca}$ is about 0.7 at $\%, 7$ at $\%$, and 5 at $\%$, for papers 1,2 and 3, respectively. This confirms the fact that much lower amount of inorganic parts can be detected in case of paper 1, while higher amounts of inorganic parts are present in papers 2 and 3. Furthermore, the increases in inorganic elements can be nicely correlated with the removal of organic parts of the coating and exposure of the inorganic particles buried underneath the organic film. The elements $\mathrm{Si}$ and $\mathrm{Al}$ correspond to the chemical composition of kaolin. While no Si or Al atoms were detected on untreated paper 3, , both of these elements were detected after plasma treatment of paper 2 and 3, which further confirms the exposure of kaolin particles. This was also observed from SEM analysis, as the kaolin parts became easily visible after plasma treatment. Furthermore, the influence of plasma treatment on gloss and printing properties was studied as one of the important functional properties of the paper. Interestingly, paper 2 exhibited the most pronounced changes in gloss after plasma treatment, both in case of unprinted and printed papers. Gloss units should be directly connected to macro- and micro-roughness of the surface, however, in our study, this was not observed, as the microporous structure was the least altered 
in the case of paper 2. However, it should be noted that paper 2 also had the highest gloss among all studied papers, and that the surface wettability in this case was also the highest. Moreover, to some extent, the nanotopography obtained on paper 2 after plasma treatment could also influence on the paper gloss. Much lower influence of plasma treatment on gloss properties of paper 1 and 3 were observed. However, a slight decrease in gloss was observed on unprinted and printed paper 1 treated for $60 \mathrm{~s}$. This can again be correlated with increased nanotopography or the formation of nanopores due to plasma etching. In the case of paper 3, no changes in gloss of printed papers were detected, although in this case, plasma significantly altered the micropore structure, which became opened. These results appear to indicate that paper gloss is more influenced by nanopore topography than by the presence of micropores. Printing properties evaluated by K\&N ink absorbency measurements can be correlated with the porosity values and the pore structure of the paper. The ink absorbency values significantly increase in the case of papers 1 and 3, but only after $10 \mathrm{~s}$ of treatment, while after $60 \mathrm{~s}$ of treatment, paper 1 exhibits similar ink absorbency as the untreated paper, while the absorbency value of paper 3 is still higher compared to the untreated paper. The increase in ink absorbency after $10 \mathrm{~s}$ for papers 1 and 3 could be ascribed to gradual opening of the micropores, which allows for the deeper penetration of ink. The decrease after $60 \mathrm{~s}$ of plasma treatment could again be ascribed to formation of nanotopography, especially in the case of paper 1, where the decrease to initial value of ink absorbency could be correlated to nanostructuring of the organic coating and formation of nanoporous morphology. The ink leveling is no longer influenced only by the opened micropore structure, which was obtained already after $10 \mathrm{~s}$ of plasma treatment. Instead, it could be presumed that ink absorbency is in this case predominantly influenced by nanopores formed on the surface, as ink no longer penetrates deep into the opened microporous structures, but is significantly retained on the nanoporous surface. In the case of paper 2 , a slight increase in ink absorption was observed after $60 \mathrm{~s}$ of treatment, which can be correlated to nanostructuring of the surface, as determined from AFM analysis. Again, the nanostructured surface could be the prevailing factor influencing ink absorbency, as no significant changes in the opened microstructure were detected on paper 2 . Interestingly, it was also shown that the high increases in surface wettability as well as in surface energy did not influence the ink absorbency, as no significant changes in wettability nor surface energy were detected between papers treated for $10 \mathrm{~s}$ and $60 \mathrm{~s}$. Thus, in the present case, gloss and printing properties were mainly influenced by surface nanotopography, which was obtained by plasma etching and is stable with time.

\section{CONCLUSIONS}

The results of this study show that different types of coatings react differently to plasma treatment and that significant changes in surface energy or wettability do not necessary lead to significant changes in printing properties. However, plasma treatment was shown to highly influence the micro- and nanoporous structure of the paper, which seems to have the most influence on the functional properties of the paper, such as printing properties. Although the plasma treatment is known to modify only the first few nanometers of the surface, it seems that in case of porous paper structure, plasma treatment selectively etches the organic components of the coating, which opens the porous microstructure also a few micrometers in depth. Such effect is stable with time and can be used in order to specifically tailor printing properties of the paper. 


\section{ACKNOWLEDGMENTS}

We would like to acknowledge support given from Vipap Videm Krško d.d. and Papirnica Vevče d.o.o.; both companies provided the coated papers used in the study. We would especially like to acknowledge Milena Resnik and Breda Ogorevc for support regarding paper properties and for a fruitful discussion. This research was funded by the RDI project Cel. Cycle: "Potential of biomass for development of advanced materials and bio-based products" (contract number OP20.00365), co-financed by the Republic Slovenia, Ministry of Education, Science and Sport and the European Union under the European Regional Development Fund, 2016-2020.

\section{REFERENCES}

1. Bollstrom, R., Tuorninen, M., Maattanen, A., Peltonen, J., Toivakka, M., 2012: Top layer coatability on barrier coatings. Progress in Organic Coatings 73: 26-32.

2. Camargo, J., Menezes, A., Cruz, N., Rangel, E., Delgado-Silva, A. , 2017: Morphological and chemical effects of plasma treatment with oxygen (O2) and sulfur hexafluoride (SF6) on cellulose Surface. Materials Research 20(Suppl. 2): 842-850.

3. Cornelius, C., Saquing, C., Venditti, R., McCord, M., Bourham, 2017: The effect of atmospheric pressure plasma on paper and pulps. BioResources 12: 8199-8216.

4. Cvelbar, U., Mozetič, M., Klanjšek-Gunde, M., 2005: Selective oxygen plasma etching of coatings. IEEE Transactions on Plasma Science 33: 236-237.

5. Dimitrakellis, P., Travlos, A., Psycharis, V.P., Gogolides, E., 2017: Superhydrophobic paper by facile and fast atmospheric pressure plasma etching. Plasma Processes and Polymers 14: 8 .

6. Fridman, A., 2008: Plasma chemistry. Cambridge University Press: New York, 42 pp.

7. Gorjanc, M., Mozetič, M., 2014: Modification of fibrous polymers by gaseous plasma: Principles, techniques and applications. Lambert Academic Publishing, Saarbrücken, 92 pp.

8. Jikan, S.S., Badarulzaman, N.A., Yahaya, S., Adamu, A.D., 2017: Delamination of kaolinite by intercalation of urea using milling. Materials Science Forum 888: 136-140.

9. Junkar, I., 2013: Plasma treatment of amorphous and semicrystalline polymers for improved biocompatibility. Vacuum 98: 111-115.

10. Karlovits, I., Lavrič, G., 2018: Influence of plasma treatment on properties of waxed papers. In: 9th International Symposium on graphic engineering and design. Novi Sad: Faculty of Technical Sciences, Pp 58-59.

11. Pawłat, J., Terebun, P., Kwiatkowski, M., Diatczyk, J., 2016: Rf atmospheric plasma jet surface treatment of paper. Journal of Physics D: Applied Physics 49( 37): 4001..

12. Pykönen, M., Sundqvist, H., Järnström, J., Kaukoniemi, O.V., Tuominen, M., Lahti, J., Peltonen, J., Fardim, P., Toivakka, M., 2008: Effects of atmospheric plasma activation on surface properties of pigment-coated and surface-sized papers. Applied Surface Science 255: 3217-3229.

13. Pykönen, M., Sundqvist, H., Kaukoniemi, O.V., Tuominen, M., Lahti, J., Fardim, P., Toivakka, M., 2008: Ageing effect in atmospheric plasma activation of paper substrates. Surface and Coatings Technology 202: 3777-3786.

14. Pykönen, M., Silvaani, H., Preston, J., Fardim, P., Toivakka, M., 2009: Plasma activation induced changes in surface chemistry of pigment coating components. Colloids and Surfaces A: Physicochemical and Engineering Aspects 352: 103-112. 
15. Pykönen, M., 2010: Influence of plasma modification on surface properties and offset printability of coated paper $\mathrm{PhD}$. Åbo Akademi University, 69 pp.

16. Skácelová, D., Kováčik, D., Homola, T., Čech, J., Černák, M., 2016: Surface modification of paper and paperboards using atmospheric pressure plasmas. In: Atmospheric pressure plasmas: processes, technology and applications. Parker, M., (Ed.), Nova Science Publishers, Inc., Hauppauge, New York, Pp 227-236.

17. Tian, J., Jarujamrus, P., Li, L., Li, M., Shen, W., 2012: Strategy to enhance the wettability of bioacive paper-based sensors. ACS Applied Materials \& Interfaces 4: 6573-6578.

18. Tuominen, M., Lahti, J., Lavonen, J., Penttinen, T., Räsänen, J., Kuusipalo, J., 2010: The influence of flame, corona and atmospheric plasma treatments on surface properties and digital print quality of extrusion coated paper. Journal of Adhesion Science and Technology 24(3): 471-492.

19. Tuominen, M., Teisala, H., Aromaa, M., Stepien, M., Makela, J.M., Saarinen, J.J., Toivakka, M., Kuusipalo, J., 2014: Creation of superhydrophilic surfaces of paper and board. Journal of Adhesion Science and Technology 28: 864-879.

20. Vaswani, S., Koskinen, J. and Hess, D., 2005: Surface modification of paper and cellulose by plasma-assisted deposition of fluorocarbon films. Surface and Coatings Technology 195(2-3): 121-129.

21. Vesel, A., Mozetič, M., Hladnik, A., Dolenc, J., Zule, J., Milošević, S., Krstulović, N., Klanjšek-Gunde, M., Hauptmann, N., 2007: Modification of ink-jet paper by oxygenplasma treatment. Journal of Physics D: Applied Physics 40(12): art. No. 3689.

22. Vesel, A., Mozetič, M., 2017: New developments in surface functionalization of polymers using controlled plasma treatments. Journal of Physics D: Applied Physics 50(29), art. No. 293001.

23. Vesel, A., Zaplotnik, R., Kovac, J., Mozetic, M., 2018: Initial stages in functionalization of polystyrene upon treatment with oxygen plasma late flowing afterglow. Plasma Sources Science \& Technology 27( 9): art. No. 094005.

24. Vohrer, U., Trick, I., Bernhardt, J., Oehr, C., Brunner, H., 2001: Plasma treatment - an increasing technology for paper restoration? Surface and Coatings Technology 142-144: 1069-1073.

25. Zhao, M., Li, H., Liu, W., Guo, Y., Chu, W., 2016: Plasma treatment of paper for protein immobilization on paper-based chemiluminescence immunodevice. Biosensors and Bioelectronics 79: 581-588.

\author{
Matej Holc, Ita Junkar* \\ Jožef Stefan Institute \\ Jamova Cesta 39 \\ Iooo Ljubljana \\ Slovenia
}

*Corresponding author: ita.junkar@ijs.si 
IgOR KaRLOVITS

Pulp And Paper Institute

BogišićEva 8

IOOO LJUBLJANA

Slovenia

David Ravnjak, Aleš Palatinus

Vevče Paper Production Mill

Papirniška Pot 25

I25 I Lubljana-Dobrunje

Slovenia 